Serhiy Buriakovskyi - Borys Liubarskyi - Artem Maslii - Danylo Pomazan - Tatyana Tavrina

\title{
RESEARCH OF A HYBRID DIESEL LOCOMOTIVE POWER PLANT BASED ON A FREE-PISTON ENGINE
}

This article describes one of the possible ways for improving the energy efficiency of shunting diesel locomotives. It means a replacing a traditional traction electric transmission with a diesel generator set with a hybrid transmission with a free-piston internal combustion engine and a linear generator. The absence of a crankshaft in an internal combustion engine makes it possible to reduce thermal and mechanical losses, which, in turn, leads to an increase in the efficiency of traction electric transmission of the diesel locomotive.

Keywords: internal combustion engine, power plant, free piston engine, linear generator, crankshaft

\section{Introduction}

On modern diesel locomotives, a generator-motor system that converts the thermal energy of fuel combustion into the kinetic energy of the piston motion is employed. The progressive motion of the piston is converted into rotational motion of the crankshaft and the generator shaft, which in the end results in the generation of an EMF generator. As a result of repeated energy conversion in the internal combustion engine (ICE), significant energy losses occur.

As mentioned in [1], in the ICE with a crankshaft, the combustion process occurs near its top dead centre (TDC); therefore the highest temperature and pressure are maintained for a relatively long time. It leads to high heat loss, which degrades the efficiency of the engine. Because of the complex design, the problem for internal combustion engines with a crankshaft is friction losses. The loss of power for friction is the major part of all mechanical losses. Mainly these losses fall on the following pairs: the piston and piston rings - cylinder walls, crankshaft and camshaft journals - plain bearings, the piston pin - piston bosses and the upper connecting rod head, the valve stem - the bushing. Losses on friction increase with increasing load on the engine, increasing crankshaft speed, rough processing of the surface of mating parts, unjustified increase in their size, the use of poor-quality oils, disruptions of the lubrication system and the cooling system and deterioration of the technical state of the engine. Losses in the mechanism of the crankshaft account for $16-19 \%$ of all mechanical losses, and the frictional losses between the piston and the cylinder liner that result from the formation of lateral forces of the piston are $42-50 \%$ [2].
Overcoming these drawbacks is possible with the development of new types of the ICE, namely engines with a free piston. In a free-piston engine, the movement of the piston is not limited to the presence of a rigid connection with the crankshaft.

The free piston engine consists of two main components: a free piston ICE and linear generator.

As opposed to common ICEs with crankshaft, pistons of the free piston engine freely move in the cylinder, which allows you to change the compression ratio and optimize the combustion process. Changing the compression ratio, this type of engine can work with a homogeneous charge ignition, which allows increasing its thermal efficiency and reducing the emissions of harmful substances into the atmosphere.

The free piston engine is simpler in design, which reduces production costs, compared to the ICE with the crankshaft. The absence of a crankshaft reduces friction losses, and the movement of a free piston can be carried out with greater acceleration. According to [3], the peak piston acceleration in a free-piston engine is about $60 \%$ higher than in a conventional engine and the free-piston engine runs less in the TDC zone, where the gas pressure and temperature are the highest. Consequently, the loss of heat in the cylinder of the free piston engine is less than that of a conventional engine.

In the context of the need to reduce the consumption of fuel and energy resources for the locomotive traction, the development and investigation of new types of power plants for rolling stock is quite urgent. As it was said in [4], at present, hybrid traction electric transmissions are increasingly used. The use of such transmission in a diesel locomotive implies the presence of an on-board energy

Serhiy Buriakovskyi ${ }^{1}$, Borys Liubarskyi ${ }^{2}$, Artem Maslii $^{3}$, Danylo Pomazan ${ }^{3} *$, Tatyana Tavrina ${ }^{4}$

${ }^{1}$ Scientific Research and Design Institute Molniya, National Technical University Kharkiv Polytechnic Institute, Ukraine

${ }^{2}$ Department of Electrical Transport and Diesel Locomotive, National Technical University Kharkiv Polytechnic Institute, Ukraine

${ }^{3}$ Department of Electroenergy, Electrical Equipment and Electromecanics, Ukrainian State University of Railway Transport, Kharkiv, Ukraine

${ }^{4}$ Department of Physics, National Technical University Kharkiv Polytechnic Institute, Kharkiv, Ukraine

*E-mail of corresponding author: danil.pomazan@ukr.net 


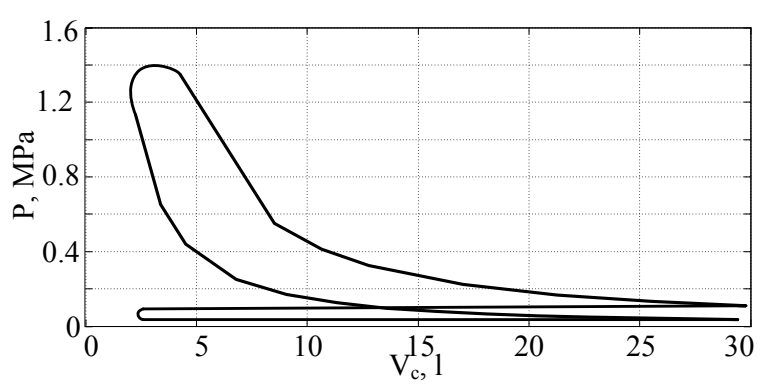

Figure 1 An indicator diagram of K6S310DR diesel engine operation

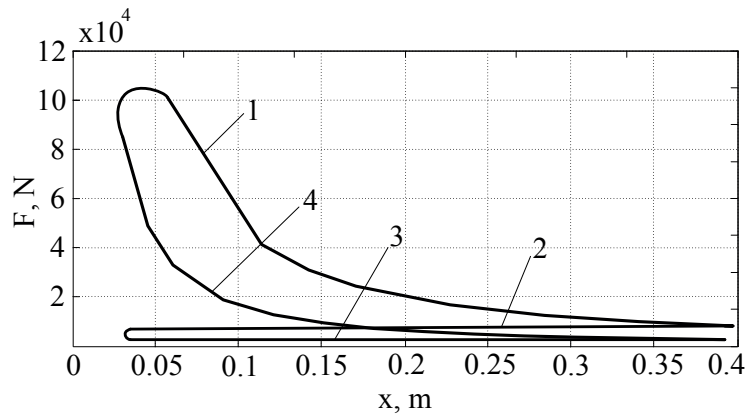

Figure 2 A force-displacement diagram of the K6S310DR diesel engine

Table 1 K6S310DR diesel engine specification

\begin{tabular}{lc}
\hline Parameter & Value \\
\hline Cylinder diameter, mm & 310 \\
Piston stroke, mm & 360 \\
Power, kW & 993 \\
Shaft speed, rpm & 750 \\
Boost pressure, kPa & 98.1 \\
Total cylinder volume, 1 & 177 \\
Compression ratio & 13 \\
\hline
\end{tabular}

storage device in the form of an accumulator, capacitor, or other types of batteries [5]. This makes it possible to reduce the capacity of the power plant and use the energy which is stored in the batteries [6]. Despite the higher efficiency of such a transmission compared to traditional, the issue of low efficiency of the power plant remains unresolved. Based on this, one of the ways to increase the efficiency of such systems is using an engine with a free piston. Because such a power unit consists of independent generator modules, it is characterized by a jog operation. This drawback is offset by the shift of the work cycles of the modules relative to each other and their work on common energy storage. Based on the foregoing, the integration of a free-piston ICE with a linear generator into a hybrid traction electric transmission will not cause additional complication of the system but will make it possible to increase the efficiency of the locomotive's power plant.

The purpose of this work is to study the working properties of a free-piston engine of a shunting diesel locomotive. To solve this problem, the design of the engine and generator was selected, and simulation models of their
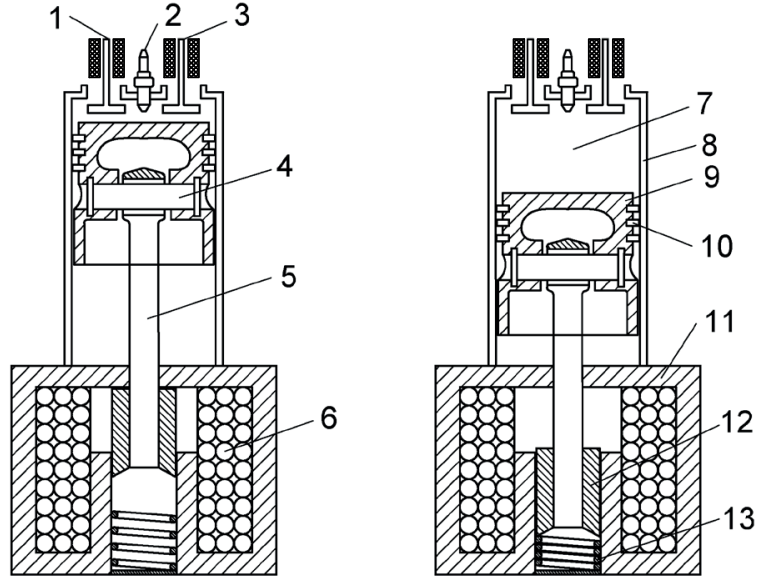

Figure 3 Free piston engine structure: 1 - inlet electromagnetic valves, 2 - heating plug, 3 - exhaust electromagnetic valves, 4 - piston pin, 5 - piston rod,

6 - coil, 7 - combustion chamber, 8 - cylinder, 9 - piston, 10 - piston rings, 11 - stator, 12 - armature, 13 - spring work, that allows to study the features of this system, were compiled.

\section{The choice of design of the internal combustion engine and generator}

The development of the design of a free-piston engine includes determining the types of an ICE and a linear generator. To unify the newly developed power plant with an ICE that currently exists on the railways, the K6S310DR diesel engine of the ChME3 shunting diesel locomotive, the technical characteristics of which are shown in Table 1, was chosen as a prototype.

The design of the new engine uses a pair of pistoncylinder, as well as the intake and exhaust systems of the existing diesel.

The choice of a linear generator is justified by the condition that it creates forces equal to those produced by the ICE's piston. Based on this, the calculation of the diesel engine working processes was carried out according to the technique given in [7]. By the calculation results, 
the indicator diagram of the diesel engine operation was plotted, which is shown in Figure 1.

For the subsequent work, the use of a diagram in the $\mathrm{P}$ and $\mathrm{V}$ axes is highly inconvenient, so the diagram shown in Figure 1 is transformed into a diagram in the axes $F$ and $\mathrm{x}$, where $\mathrm{F}$ is the force acting on the piston, $\mathrm{x}$ is the displacement of the piston. The diagram of the dependence of the force acting on the piston against displacement is shown in Figure 2.

In order to reach the maximum coefficient of efficiency, the mechanical characteristic of the generator should be as close as possible to the work diagram of the diesel engine. In the operation of the diesel engine, four main modes can be distinguished: 1) working stroke, 2) exhaust, 3) cylinder filling, 4) compression.

As a linear generator, an electromagnet was chosen as its characteristic has a shape similar to the shape of the compression and expansion curves of a diesel engine. The use of this design of an electromechanical converter (EMC) does not allow for a four-stroke mode of operation of the ICE. The use of electromagnetic inlet and outlet valves makes it possible to put the ICE into the two-stroke mode that will be considered further.

The result of the analysis done is the choice of the design of a free piston engine for a hybrid diesel locomotive, which is shown in Figure 3.

The linear generator (Figure 3) in the form of electromagnet contains coil 6, armature 12 and stator 11. The generator has two basic positions: coincided one and unmatched one, the connection of the armature with the rod is designed so that in the position of the piston at the top dead center, the armature was in the coincided position. The use of a two-stroke internal combustion engine involves two strokes of the piston, in which the cylinder is filled and the fuel-air mixture is compressed, the piston is stroked and gas is exhausted. The main is the stroke of the piston. During the stroke of the piston, the generator generates electrical energy, which is accumulated in the storage system. As a storage system, a storage battery or a supercapacitor battery and their combination, can be used. During compression of the fuel-air mixture, the generator operates in engine mode and moves the piston. The design provides for the use of a spring 13 , it serves to increase the force developed by the electromagnet at the beginning of the compression stroke of the fuel-air mixture.

\section{Development of a simulation model of the engine work}

The work of an EMC of electromagnetic type is described by the following system of equations:

$$
\left\{\begin{array}{l}
\frac{d i}{d t}=\frac{1}{\frac{\partial \Psi(i, x)}{\partial i} \cdot\left[E-r i-\frac{\partial \Psi(i, x)}{\partial x} \cdot v\right]} \\
\frac{d v}{d t}=\frac{F_{e l}(i, x)+F_{s}-F_{r}}{m} \\
\frac{d x}{d t}=v .
\end{array}\right.
$$

where:

$i$ - stator current,

$\Psi$ - the armature flux linkage,

$E$ - the power supply voltage,

$r$ - the coil resistance,

$x$ - the translation of generator armature,

$v$ - the speed,

$F_{e l}$ - the electromagnetic force,

$F_{s}$ - the spring pressure,

$F_{r}$ - the resistance force.

In the linear EMF of electromagnetic type, the developed force and flux linkage of the winding depend on armature floating; therefore, these parameters were calculated with the aid of the FEMM software package [8]. In this package, the calculation is done by the finite element method, and the calculated zone is divided into elementary triangular zones (Figure 4.1). The distribution of the magnetic field in the stator and the armature of the electromagnet is shown in Figure 4.2.

Using a subroutine written in a text file in the Lua programming language, the calculation process was computerised. Whereupon the boundary conditions are the movement of the armature and the stator from the coincided position to the unmatched one that comprises $315 \mathrm{~mm}$, and the permissible value of MMS at the level of $40000 \mathrm{~A}$.

The results of the calculation are the obtained values of the flux linkage and the force put into action by the magnet at different values of displacement and MMS of the armature winding, which are presented in Figures 5 and 6 .

To obtain continuous dependencies of flux linkage, the results of digital modelling were approximated by continuous functions. When choosing the type of function, the following tasks were solved:

- the function and its derivatives for moving the armature at the beginning and end of the interval on which the approximation is carried out should be the same [9];

- the proposed function must have a fairly simple form of analytic partial derivatives with respect to all coordinates [10].

Taking into consideration the said above, it is proposed the function of the following form:

$$
\begin{aligned}
& f(i, x)=\sum_{l=1}^{m}\left[\left(\sum_{h=0}^{n} a a_{h} \cdot i^{h}\right) \times \cos (l x)+\right. \\
& \left.+\left(\sum_{h=0}^{n} b b_{h} \cdot i^{h}\right) \sin (l x)\right]+\sum_{h=0}^{n} c c_{h} \cdot i^{h}
\end{aligned}
$$

where:

$a a_{h}, b b_{h}, c c_{h}$ - - polynomial coefficients,

$i$ - the stator current,

$x$ - the armature translation,

$l$ - the harmonic number.

To determine the coefficients of the polynomial, we used the method based on Chebyshev polynomials on the set of equidistant points [11].

Reduction of the order of the mathematical model without limitation can be obtained if the force is determined from the results of the calculation of the magnetic field by 

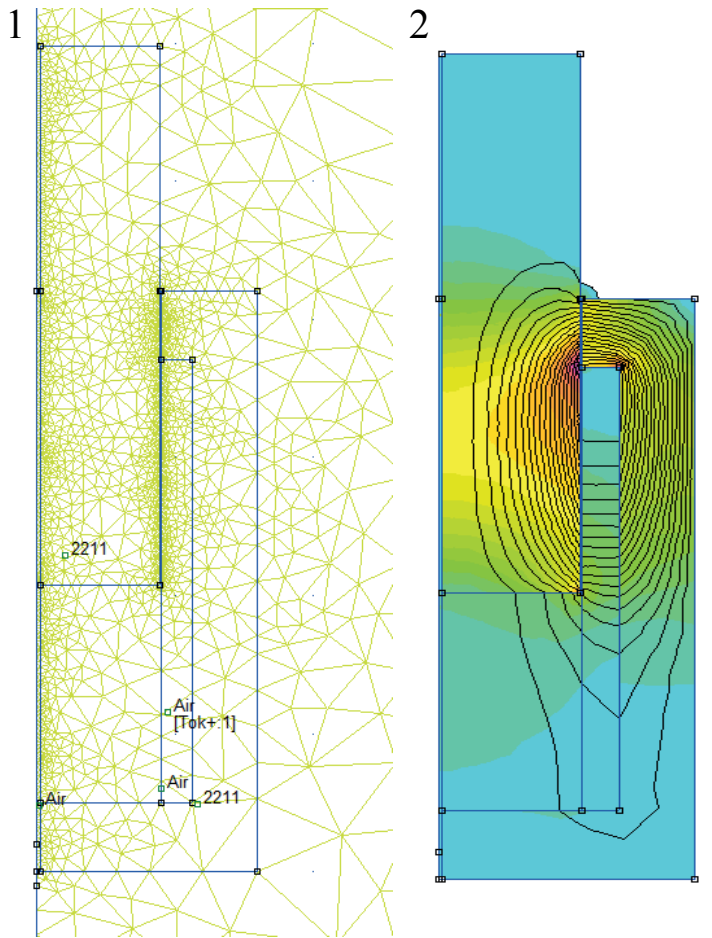

Figure 4 Estimated area (1) and magnetic flux density distribution in the generator (2)

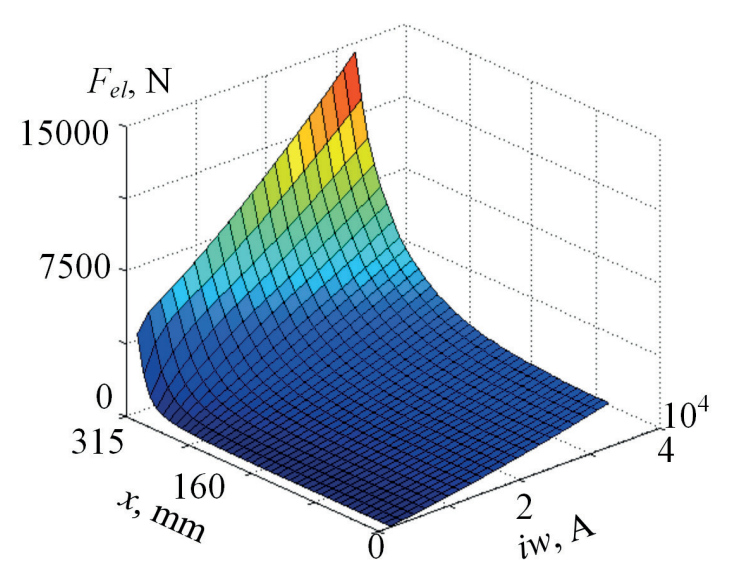

Figure 5 Values of flux linkage obtained as a result of calculation

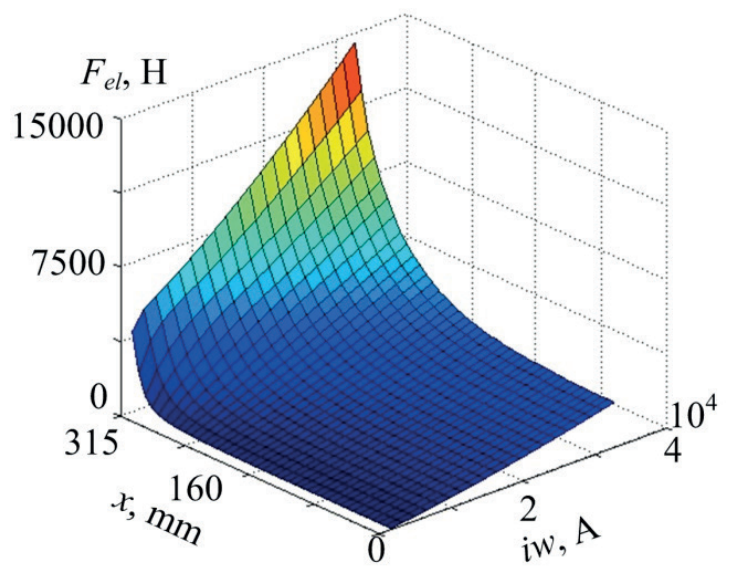

Figure 6 Values of the force obtained as a result of calculation

$Z J, Z K$ - the bias of current and clearance, respectively, $J, K$ - the degrees of the approximating polynomial of current and clearance, respectively.

To create a simulation model, functional diagrams of

$$
F_{e}(i, x)=\sum_{j=0}^{J F} \sum_{k=0}^{K F}\left(\begin{array}{l}
m a_{j k}(M J F \cdot i+Z J F)^{j} \times \\
\times(M K F \cdot x+Z K F)^{k}
\end{array}\right),
$$

where:

$m a_{j k}$ - polynomial coefficients that are determined by the Chebyshev method,

$M J F, M K F$ - scale current and clearance coefficients, respectively,

$Z J F, Z K F$ - the bias of current and clearance, respectively.

The polynomial describing the function of stator winding flux linkage has the following form:

$\Psi(i, x)=w \sum_{j=0}^{J} \sum_{k=0}^{K}\left(\begin{array}{l}a a_{j k}(M J \cdot i+Z J)^{j} \times \\ \times(M K \cdot x+Z K)^{k}\end{array}\right)$,

where:

$a a_{j k}$-polynomial coefficients for winding that are determined by the Chebyshev method,

$w$ - number of winding turns,

$M J, M K$ - scale current and clearance coefficients, respectively, the free piston engine, which are shown in Figures 5 and 6 , were drawn up.

On the basis of the functional diagrams (Figures 7 and 8) and the system of Equations (1), a structural diagram of the model of the operation of a free piston engine with linear EMC was drawn up (Figure 9).

On the basis of the structural scheme, an imitation model of the engine operation was developed. The simulation was performed in the MatLab environment [1213].

The ICE model is based on the diagram of its operation (Figure 2) approximated by polynomials. The linear EMC model is constructed on the basis of the system of Equations (1). The electronic commutator includes 2 transistors and 2 reverse diode, the models of which were taken from the SimPowerSystems section [14-16]. In the motor mode, the winding is powered through transistors, and in the generator mode current flows through the diodes. A capacitor, that is charged by EMC in generation mode and 


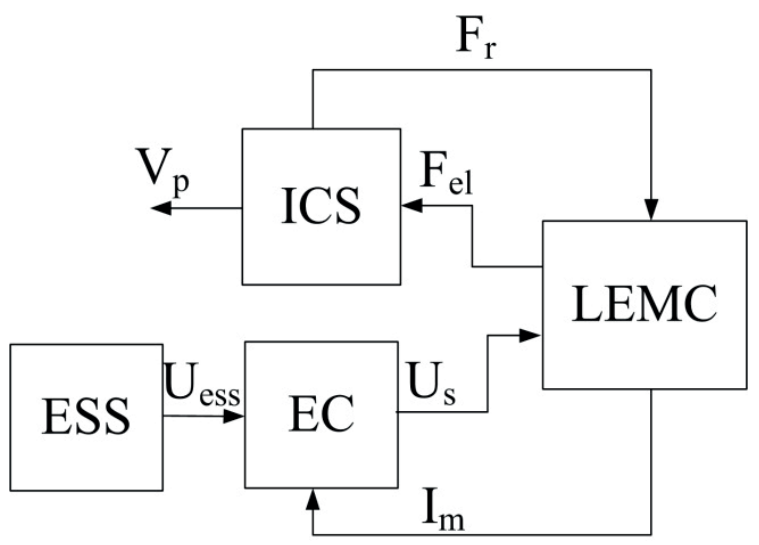

Figure 7 Flow diagram of free piston engine operation in compression mode: ESS - energy storage system, ICS internal combustion system, EC - electronic commutator, LEMC - linear electromechanical converter, $U_{\text {ess }}-$ supply voltage of EC from ESS, $U_{s}$ - armature supply voltage, $I_{m}$ engine current, $F_{e l}$ - electromagnetic force, $F_{r}-$ ICE resistance force, $V_{p}$ - piston speed

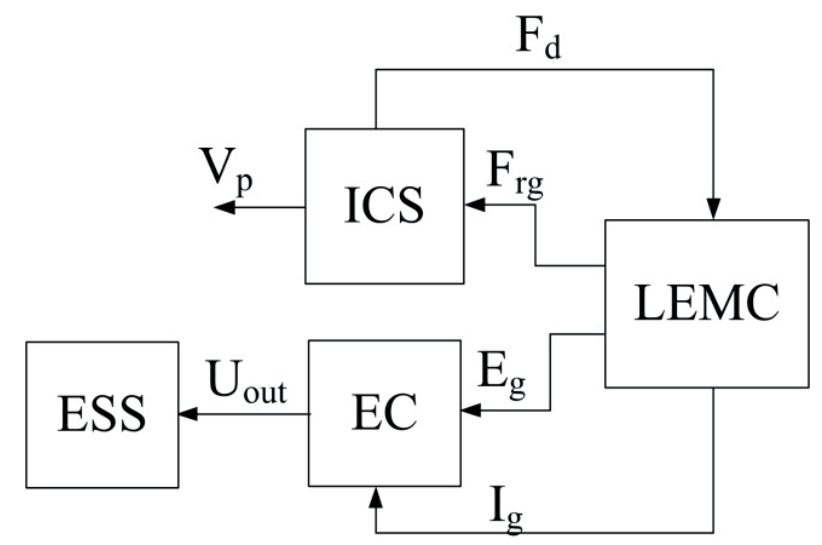

Figure 8 Flow diagram of free piston engine operation in operating motion mode: $U_{\text {out }}$ - output voltage of EC for charging ESS, $E_{g}$ - generator voltage, $I_{g}$ - generator current, $F_{r g}$ - generator resistance force, $F_{d}$ - force generated by the working gases of a diesel engine, $V_{p}$ - piston speed

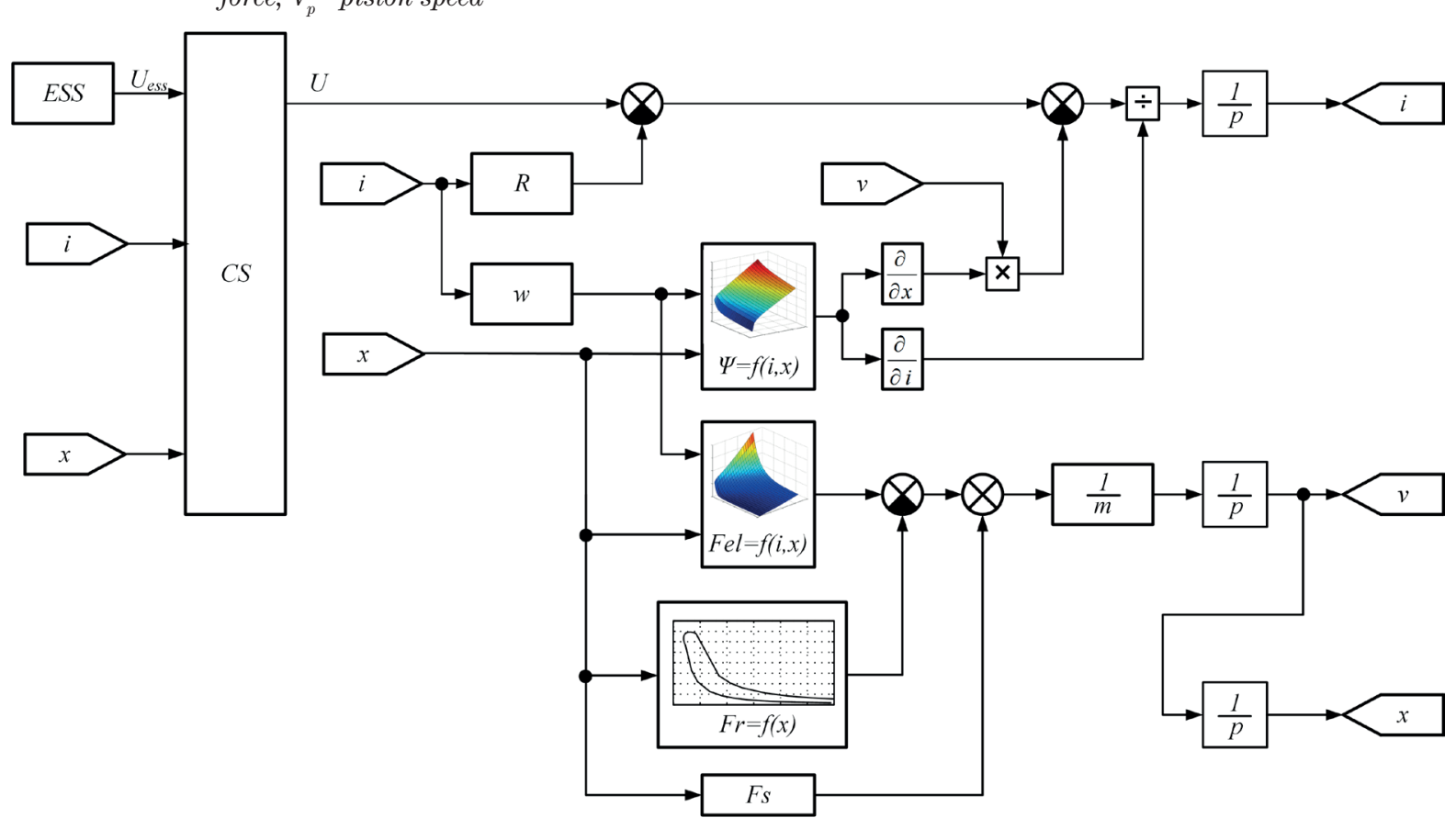

Figure 9 Free piston engine operation flow chart

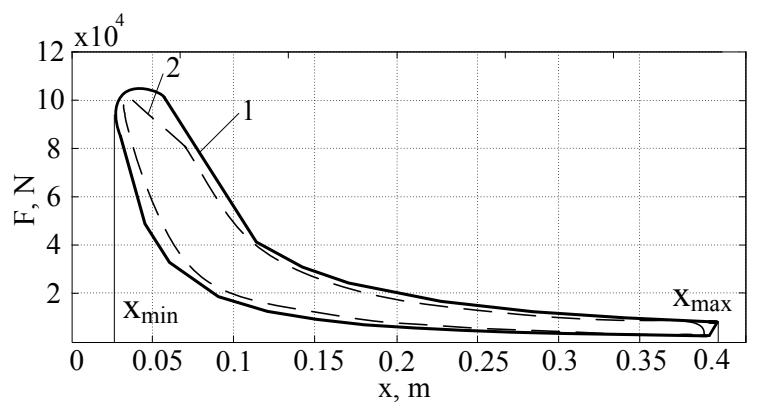

Figure 10 Free piston engine operation simulation results: 1 - force of ICE, 2 - force of linear EMC 
supply it in an engine mode, was used as an energy storage device.

As a result of the simulation, oscillograms of the forces of one module generator, that includes one cylinder of K6S310DR diesel engine and one linear generator, are obtained (Figure 10).

The difference between the voltage values on the capacitor at the beginning of the cycle and at its end was $34 \mathrm{~V}$; the average speed of the piston was $10 \mathrm{~m} / \mathrm{s}$. Based on the obtained diagram (Figure 9), according to Equations (5) and (6), the useful powers of the ICE cylinder and linear generator were calculated:

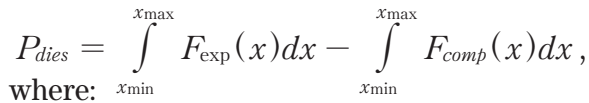

$x_{\text {min }}$ - minimum piston movement,

$x_{\text {max }}$ - maximum piston movement,

$F_{\text {exp }}$ - ICE force during expansion stroke,

$F_{\text {comp }}$ - force required to compress the fuel-air mixture.

$$
P_{\text {gen }}=\int_{x_{\min }}^{x_{\max }} F_{\text {gen }}(x) d x-\int_{x_{\min }}^{x_{\max }} F_{e n g}(x) d x,
$$

where:

$x_{\min }$ - minimum piston movement,

$x_{\text {max }}$ - maximum piston movement,

$F_{g e n}$ - EMC force during a power generation mode,

$F_{\text {eng }}$ - EMC force in engine mode.

For the diesel engine, the useful power was $207.6 \mathrm{~kW}$, and for the generator $152.3 \mathrm{~kW}$.

The coefficient of the full utilization of the diesel engine power, which is equal to the ratio of the generator power to the diesel engine power, was $73.36 \%$. At the same time, the fuel explosion energy not used by the generator is accumulated in the spring, which allows increasing the starting force of the EMC in the engine mode.

\section{Conclusions}

The use of a free piston engine with a linear generator of electromagnetic type as a diesel locomotive power plant is proposed. The suggested design has fewer parts and allows excluding the appearance of lateral forces acting on the piston. As a prototype and for the purpose of unifying the engines, the K6S310DR diesel engine from the ChME3 diesel locomotive is taken as a basis. Under the conditions of the greatest approximation of the forces of the internal combustion engine and the strength of the linear generator, the configuration of the generator is chosen. As a generator a linear electromagnetic generator was employed. For this type of generator the change in magnetic induction depending on the position of the armature is inherent; for this reason, the values of force and flux linkage of the winding depending on the movement of the armature were calculated. The values obtained as a result of this calculation were approximated by Chebyshev polynomials to obtain continuous dependencies throughout the calculation section. Functional and structural schemes of the simulation model of the engine operation were drawn. In the MatLab package environment, the suggested system was simulated and the graphs of the realization of the forces of the ICE and LEMC were obtained. The useful power of the diesel engine was $207.6 \mathrm{~kW}$, and for the generator $152.3 \mathrm{~kW}$, while the coefficient of the full utilization of the diesel power was $73.36 \%$.

The suggested design of the power plant is a promising direction in the development of transport engineering. The use of different types of linear EMCs, in the future, allows us to work not only on two-stroke cycles of a diesel engine but also on other, more efficient thermodynamic cycles.

\section{References}

[1] BAPI RAJU, V., PHANINDRA, Y. B. S. Optimization of internal combustion engine piston. International Journal for Research in Applied Science and Engineering Technology [online]. 2018, 6(VI), p. 1699-1705 [accessed 2019-10-12]. ISSN 2321-9653. Available from: https://doi.org/10.22214/ijraset.2018.6250

[2] ISERMANN, R. On the control and diagnosis of internal combustion engines. In: Combustion Engine Diagnosis [online]. Berlin, Heidelberg: Springer Vieweg, 2017, ATZ/MTZ-Fachbuch book series. ISBN 978-3-662-49466-0. eISBN 978-3-662-49467-7, p. 51-73 [accessed 2019-10-13]. Available from: https://doi.org/10.1007/978-3-662-49467-7_3

[3] YUAN, C., XU, J., HE, Y. Parametric study on the starting of a free-piston engine alternator. International Journal of Engine Research [online]. 2018, 19(4), p. 411-422 [accessed 2019-10-11]. ISSN 1468-0874, eISSN 2041-3149. Available from: https://doi.org/10.1177/1468087417712161

[4] CIPEK, M., PAVKOVIC, D., KLJAIC, Z., MLINARIC, T. Assessment of battery-hybrid diesel-electric locomotive fuel savings and emission reduction potentials based on a realistic mountainous rail route. Energy [online]. 2019, 173, p. 1154-1171 [accessed 2019-10-11]. ISSN 1468-0874, eISSN 2041-3149. Available from: https://doi.org/10.1016/j.energy.2019.02.144

[5] YATSKO, S., SIDORENKO, A., VASHCHENKO, Y., LYUBARSKYI, B., YERITSYAN, B. Method to improve the efficiency of the traction rolling stock with onboard energy storage. International Journal of Renewable Energy Research [online]. 2019, 9(2), p. 848-858 [accessed 2019-07-07]. eISSN 1309-0127. Available from: https://www.ijrer.org/ijrer/index.php/ijrer/article/view/9143

[6] BURIAKOVSKYI, S., BABAIEV, M., LIUBARSKYI, B., MASLII, A., KARPENKO, N., POMAZAN, D., MASLII, A., DENYS, I. Quality assessment of control over the traction valve-inductor drive of a hybrid diesel locomotive. Eastern- 
European Journal of Enterprise Technologies [online]. 2018, 2(91), p. 68-75 [accessed 2019-07-07]. ISSN 1729-3774, eISSN 1729-4061. Available from: https://doi.org/10.15587/1729-4061.2018.122422

[7] BARI, S. Diesel engine. Combustion, emissions and condition monitoring. London: IntechOpen, 2013. ISBN 978-953-51-6335-0.

[8] Finite element method magnetics: documentation [online]. [Viewed 2019-04-18]. Available from: http://www.femm.info/ wiki/Documentation/

[9] KUZnetsov, B., TUREnKO, A., NIKITINA, T., VOLOSHKO, A., KOLOMIETS, V. Method of synthesis of closed-loop systems of active shielding magnetic field of power transmission lines. Technical Electrodynamics [online]. 2016, 4, p. 8-10 [accessed 2019-09-10]. ISSN 1607-7970, eISSN 2218-1903. Available from: https://doi.org/10.15407/techned2016.04.008

[10] SEZEN, S., KARAKAS, E., YILMAZ, K., AYAZ, M. Finite element modeling and control of a high-power SRM for hybrid electric vehicle. Simulation Modelling Practice and Theory [online]. 2016, 62, p. 49-67 [accessed 2019-09-10]. ISSN 1569-190X, eISSN 1878-1462. Available from: https://doi.org/10.1016/j.simpat.2016.01.006

[11] HELMUT, P. Representing derivatives of Chebyshev polynomials by Chebyshev polynomials and related questions. Open Mathematics [online]. 2017, 15(1), p. 1156-1160 [accessed 2019-08-07]. ISSN 2391-5455. Available from: https://doi.org/10.1515/math-2017-0096

[12] Modeling - MATLAB \& Simulink - MathWorks [online] [Viewed 2018-09-18]. Available from: https://www.mathworks. com/help/simulink/modeling.html

[13] PERELMUTER, V. Electrotechnical systems simulation with Simulink ${ }^{\circledR}$ and SimPowerSystems ${ }^{\mathrm{TM}}$. Boca Raton: CRC Press, 2013. ISBN 9781315216430.

[14] KANUCH, J., GIROVSKY, P. Analysis of the PM motor with external rotor for direct drive of electric wheelchair. Communications - Scientific Letters of the University of Zilina [online]. 2019, 21(3), p. 66-71 [accessed 2019-1007]. ISSN 1335-4205, eISSN 2585-7878. Available from: http://komunikacie.uniza.sk/index.php/communications/article/ view/1507

[15] Buriakovskyi, S., LIUbARSKYI, B., MASliI, A., POMAZAN, D., PANCHENKO, V., MASLII, A. Mathematical modelling of prospective transport systems electromechanical energy transducers on basis of the generalized model. In: 9th International Conference on Advanced Computer Information Technologies ACIT 2019 : proceedings. 2019. ISBN 978-1- 7281-0449-2, p. 76-79.

[16] KALAIVANI, L., SUBBURAJ, P., WILLJUICE IRUTHAYARAJAN, M. Speed control of switched reluctance motor with torque ripple reduction using non-dominated sorting genetic algorithm. International Journal of Electrical Power and Energy Systems [online]. 2013, 53, p. 69-77 [accessed 2019-09-10]. ISSN 0142-0615. Available from: https://doi.org/10.1016/j.ijepes.2013.04.005 